\title{
ANALISIS PERTUMBUHAN EKONOMI DAN KETIMPANGAN PENDAPATAN ANTAR KABUPATEN DI PROVINSI SULAWESI BARAT
}

\author{
Muh. Hamid ${ }^{1}$ \\ Siradjuddin ${ }^{2}$ \\ Bahrul Ulum Rusydi ${ }^{3}$
}

\begin{abstract}
ABSTRAK
Ketimpangan masih menjadi masalah yang harus di perhatikan dalam pembangunan di setiap wilayah terutama di Provinsi Sulawesi Barat sebagai Provinsi baru di Indonesia, hal ini mendorong peneliti melihat bagaimana laju pertumbuhan ekonomi dan tingkat ketimpangan antar Kabupaten di Provinsi Sulawesi Barat dengan melihat bagaimana pola pertumbuhan ekonomi dan tingkat ketimpangan pendapatan antar Kabupaten di Provinsi Sulawesi Barat tahun 2011-2015.

Penelitian ini menggunakan metode penelitian kuantitatif dengan menggunakan data sekunder yaitu: pendapatan perkapita dan jumlah penduduk selama 5 tahun dari tahun 2011-2015. Metode analisis data yang digunakan dalam penelitian ini adalah Analisis Tipologi Klassen, untuk mengelompokkan tiap-tiap wilayah berdasarkan laju pertumbuhan ekonomi dan pendapatan perkapita serta mengelompokkan dalam empat Kuadran, kemudian menganalisis dengan menggunakan Indeks Williamson untuk melihat tingkat ketimpangan berdasarkan pendapatan perkapita dan jumlah penduduk serta pembuktian Hipotesis Kuznets tentang U-Terbalik.

Hasil penelitian dengan Analisis Tipologi Klassen menggambarkan bahwa ada perbedaan pola dalam pertumbuhan ekonomi Provinsi Sulawesi Barat yaitu: ada dua wilayah dalam Kuadran I (tumbuh cepat) dan empat wilayah dalam Kuadran IV (relatif tertinggal), serta dalam analisis Indeks Williamson memperlihatkan bahwa ketimpangan di Provinsi Sulawesi Barat masih tergolong rendah dengan rata-rata 0,350 . Sementara Hipotesis Kuznets tentang U-Terbalik yang menggambarkan hubungan antara pertumbuhan dengan indeks ketimpangan belum berlaku di Provinsi Sulawesi barat tahun 2011-2015.
\end{abstract}

Kata kunci: Pertumbuhan Ekonomi, Ketimpangan, Hipotesis Kuznets

\section{PENDAHULUAN}

Pada hakikatnya pembangunan ekonomi bertujuan untuk meningkatkan kesejahteraan masyarakat. Oleh karena itu dalam rangka peningkatan

\footnotetext{
1 UIN Alauddin Makassar, muh.hamid0711@gmail.com

2 UIN Alauddin Makassar, siradjuddin.uin@gmail.com

3 UIN Alauddin Makassar, bahrul.rusydi@gmail.com
} 
kesejahteraan masyarakat diperlukan pertumbuhan ekonomi yang baik dan distribusi pendapatan yang merata tanpa adanya disparitas. Selain untuk mensejahterakan masyarakat, pembangunan ekonomi juga bertujuan untuk mengejar ketertinggalan serta mensejajarkan setiap daerah kabupaten yang sudah maju. Ada beberapa faktor yang menjadi tolak ukur keberhasilan pembangunan ekonomi diantaranya pertumbuhan ekonomi dan disparitas pendapatan antar penduduk. ${ }^{4}$

Karena itu, setiap daerah selalu menetapkan target laju pertumbuhan yang tinggi di dalam perencanaan dan tujuan pembangunan daerahnya. Pertumbuhan ekonomi yang tinggi dan berkelanjutan merupakan kondisi utama bagi kelangsungan pembangunan ekonomi. Karena penduduk bertambah terus, maka "dibutuhkan penambahan pendapatan setiap tahunnya, hal ini dapat terpenuhi lewat peningkatan output secara agregat baik barang maupun jasa atau Produk Domestik Bruto (PDB) setiap tahunnya" ${ }^{5}$

Pelaksanaan dari otonomi daerah mulai dilaksanakan pada tahun 2001 yang mana wewenang pengelolaan sistem pemerintahan yang bersinggungan langsung dengan masyarakat sepenuhnya diserahkan kepada pemerintah daerah. Kebijakan otonomi daerah di bawah:

Undang-Undang Nomor 32 Tahun 2004 tentang Pemerintah Daerah, menyebutkan "Otonomi Daerah" adalah hak, wewenang, dan kewajiban daerah otonom untuk mengatur dan mengurus sendiri urusan pemerintahan dan kepentingan masyarakat setempat sesuai dengan peraturan perundangundangan.

Undang-Undang Nomor 33 Tahun 2004 tentang Otonomi Daerah dimaksudkan untuk mendukung pendanaan atas penyerahan urusan kepada pemerintahan daerah yang diatur dalam undang-undang tentang pemerintahan daerah.

Penyebab ketimpangan antar wilayah biasanya berupa perbedaan sumber daya alam seperti adanya kandungan alam minyak dan gas atau tingkat kesuburan lahan antara daerah satu dengan daerah lain yang tidak sama. Dengan adanya perbedaan itu membuat kegiatan produksi daerah yang memiliki sumber daya

\footnotetext{
${ }^{4}$ Todaro, "E konomi Pembangunan" Erlangga, Jakarta, 2006

5 Rendi Hangga Kusuma, Jurnal, "Analisis Struktur Pertumbuhan Ekonomi dan Ketimpangan Pendapat Antar Daerah di Provinsi Jawa Tengah, 2004-2008”, 2011
} 
alam bagus lebih efisien dengan biaya yang relatif lebih murah dibandingkan daerah lain. "Sehingga tingkat pertumbuhan ekonomi daerah yang memiliki kondisi alam lebih bagus akan lebih cepat dibandingkan daerah lain."

Sulawesi Barat sudah memiliki Enam Daerah Kabupaten. Kabupaten termuda adalah Mamuju Tengah hasil pemekaran dari Kabupaten Mamuju. Penyusunan ini menggunakan tahun dasar yang baru yakni 2011. Data series PDRB (Produk Domestik Regional Bruto) merupakan salah satu alat ukur keberhasilan pembangunan. Data PDRB dapat dijadikan sebagai dasar penentuan target pertumbuhan ekonomi dan sebagai bahan evaluasi keberhasilan pembangunan yang telah dilakukan. Pengukuran dengan data PDRB dapat menggambarkan besaran alokasi masing-masing kategori dalam menciptakan perekonomian (struktur ekonomi) serta pertumbuhan per kategori disamping pertumbuhan secara total.

Dari penjabaran tersebut, maka penelitian hendak membahas tentang perbedaan pola ekonomi antar kabupaten di Sulawesi Barat, tingkat ketimpangan di Sulawesi Barat, dan pengujian Hipotesis Kuznets tentang U terbalik di Sulawesi Barat.

\section{TINJ AUAN PUSTAKA}

Paul A. Samuelson (1997) mendefinisikan bahwa "pertumbuhan ekonomi menunjukkan adanya perluasan atau peningkatan dari gross domestic product potensial atau output dari suatu negara". ${ }^{7}$ Ada empat faktor yang menyebabkan pertumbuhan ekonomi, yaitu :

a) Sumber daya manusia, yaitu meliputi tenaga kerja, keterampilan, pengetahuan dan disiplin kerja. Faktor ini merupakan faktor penting dalam pertumbuhan ekonomi. Kenyataan dalam dunia ekonomi unsur lain dalam produksi seperti barang-barang modal, bahan mentah dan teknologi dapat dibeli atau dipinjam. Sebuah negara mungkin dapat membeli peralatan telekomunikasi paling modern, komputer dan lain-lain.

b) Pembentukan modal. Akumulasi modal, seperti yang kita ketahui membutuhkan pengorbanan konsumsi untuk beberapa tahun lamanya.

\footnotetext{
${ }^{6}$ Sjafrizal "K etimpangan Antar Wilayah" Niaga Swadaya, Jakarta, 2008

7 Todaro, Ekonomi Pembangunan" Erlangga, Jakarta, 2006
} 
Negara yang tumbuh dengan cepat cenderung untuk melakukan investasi besar besaran pada barang modal baru, pada negara-negara yang pertumbuhannya paling cepat, 10 sampai 20 persen dari pendapatannya menjadi dana pembentukan modal.

c) Perubahan teknologi dan inovasi. Sebagai tambahan bagi ketiga faktor klasik tersebut, pertumbuhan ekonomi tergantung pada fungsi keempat yang vital yaitu teknologi. Dalam sejarahnya pertumbuhan bukan merupakan proses replikasi sederhana, penambahan pabrik dan pekerja yang serupa satu sama lain.

Boediono (1999) mendefenisikan bahwa pertumbuhan ekonomi adalah "suatu proses dari kenaikan output perkapita dalam jangka panjang". ${ }^{8}$ Pertumbuhan ekonomi disini meliputi tiga aspek :

a) Pertumbuhan ekonomi merupakan suatu proses (aspek ekonomi), suatu perekonomian berkembang atau berubah dari waktu ke waktu.

b) Pertumbuhan ekonomi berkaitan dengan adanya kenaikan output perkapita, dalam hal ini ada dua aspek penting, yaitu: output total dan jumlah penduduk. Output perkapita adalah output total dibagi dengan jumlah penduduk.

c) Pertumbuhan ekonomi dikaitkan dengan perspektif waktu, suatu perekonomian dikatakan tumbuh bila dalam jangka waktu yang cukup lama (lima tahun) mengalami kenaikan output perkapita.

Menurut Syafrizal, ketimpangan yang terjadi antar wilayah disebabkan oleh "perbedaan kekayaan sumber daya alam yang dimiliki dan perbedaan kondisi demografi yang terdapat pada masing-masing wilayah, sehingga tiap daerah mempunyai kemampuan yang berbeda-beda dalam proses pembangunan". ${ }^{9}$ Perbedaan wilayah ini yang menimbulkan adanya wilayah maju dan wilayah terbelakang.

\footnotetext{
${ }^{8}$ Todaro, Ekonomi Pembangunan, Erlangga, Jakarta, 2006

${ }^{9}$ Sjafrizal, Ekonomi Regional Teori dan Aplikasi, Niaga Swadaya, Jakarta, 2008.
} 


\section{METODE PENELITIAN}

1. Jenis Penelitian

Jenis penelitian yang digunakan adalah penelitian kuantitatif yaitu data yang berupa angka misalnya: pertumbuhan ekonomi, pendapatan per kapita dan data lain yang relevan dengan penelitian ini, yang berkaitan dengan pertumbuhan ekonomi Provinsi Sulawesi Barat pada tahun 2011-2015.

\section{Lokasi Penelitian}

Penelitian ini di lakukan di kantor Badan Pusat Statistik (BPS) Provinsi Sulawesi Barat yang berpusat di Daerah/Kota Kabupaten Mamuju sebagai Ibu Kota Provinsi Sulawesi Barat. Peneliti menggunakan data setiap Kabupaten dan data Provinsi Sulawesi Barat.

\section{Analisis Tipologi Klassen.}

Analisis Tipologi Klassen digunakan untuk mengetahui gambaran tentang struktur pertumbuhan ekonomi daerah. Sjafrizal, menjelaskan bahwa dengan menggunakan alat analisis ini dapat diperoleh empat klasifikasi pertumbuhan masing-masing daerah yaitu daerah pertumbuhan cepat (rapid growth region), daerah tertekan (retarded region), daerah sedang berkembang (growing growth) dan daerah relative tertinggal (relatively backward region). Lebih jelasnya dapat digambarkan sebagai berikut:

\begin{tabular}{l|l|l}
\hline \multicolumn{1}{c|}{ Paju } \\
Pertumbuhan & $y_{i}^{d}>y_{i}^{n}(+)$ & $y_{i}^{d}<y_{i}^{n}(-)$ \\
\hline$r_{i}^{d}>r_{i}^{n}(+)$ & $\begin{array}{l}\text { Daerah maju dan } \\
\text { tumbuh cepat }\end{array}$ & $\begin{array}{l}\text { Daerah berkembang } \\
\text { cepat tapi tidak maju }\end{array}$ \\
\hline$r_{i}^{d}<r_{i}^{n}(-)$ & $\begin{array}{l}\text { Daerah maju tapi } \\
\text { tertekan }\end{array}$ & $\begin{array}{l}\text { Daerah relatif } \\
\text { tertinggal }\end{array}$ \\
\hline
\end{tabular}

Sumber: Sjafrizal, (1997)

Keterangan:

$r_{i}^{d}$ : Laju pertumbuhan Kabupaten i

$r_{i}^{n}$ : Laju pertumbuhan total PDRB Provinsi Sulawesi Barat.

$y_{i}^{d}$ : Pendapatan perkapita Kabupaten i.

$y_{i}^{n}$ : Pendapatan perkapita Provinsi Sulawesi Barat. 
4. Analisis Tingkat Ketimpangan Regional.

Alat analisis tingkat ketimpangan regional yang digunakan dalam penelitian ini adalah Indeks Williamson. Indeks ketimpangan regional ini diformulasikan sebagai berikut:

$$
\mathrm{IW}=\frac{\sqrt{\sum(Y-Y)^{2}(f / n)}}{Y}
$$

Keterangan:

IW : Indeks Williamson.

Yi : Pendapatan perkapita di Kabupaten.

Y : Pendapatan perkapita di Provinsi.

fi : Jumlah penduduk di Kabupaten.

$\mathrm{n}$ : Jumlah penduduk di Provinsi.

Formula Indeks Williamson menggunakan PDRB perkapita dan jumlah penduduk dimana nilai yang diperoleh antara nol dan satu atau $(0<\mathrm{W}<1)$. Dengan indikator bahwa apabila semakin kecil nilai Indeks Williamson maka menunjukkan ketimpangan yang semakin rendah begitu pula sebaliknya semakin besar angka Indeks Williamson menunjukkan ketimpangan yang semakin tinggi.

\section{Pembuktian Kuznets.}

Kuznets mengatakan bahwa tahap awal pertumbuhan ekonomi, distribusi pendapatan cenderung memburuk, dan tahap selanjutnya, distribusi pendapatannya akan membaik, namun pada suatu waktu akan terjadi peningkatan disparitas lagi dan akhirnya menurun lagi, jika digambarkan akan membentuk kurva $U$ terbalik.

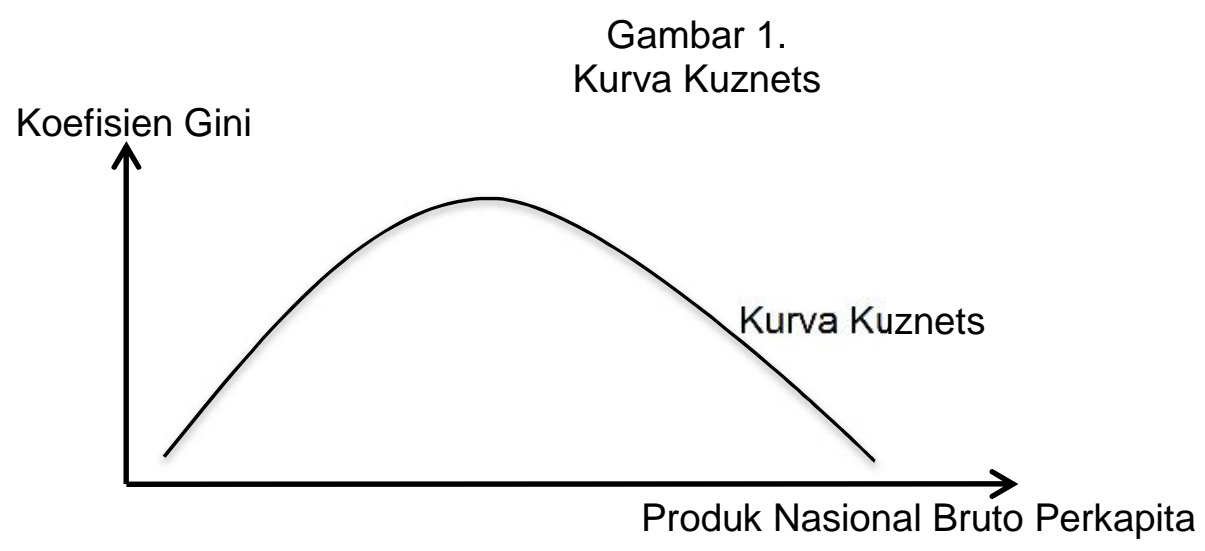

Sumber: Todaro, 2003 


\section{HASIL DAN PEMBAHASAN}

\section{Hasil Analisis Tipologi Klassen}

Berdasarkan hasil Klasifikasi Tipologi Klassen diperoleh klasifikasi pertumbuhan ekonomi antar Kabupaten di Provinsi Sulawesi Barat Tahun 20112015.

Tabel 2.

Klasifikasi Tipologi Klassen pendekatan antar Kabupaten di Provinsi Sulawesi Barat tahun 2011-2015.

\begin{tabular}{l|l|l}
\hline Laju Pertumbuhan & $y_{i}^{d}>y_{i}^{n}(+)$ & $y_{i}^{d}<y_{i}^{n}(-)$ \\
\hline$r_{i}^{d}>r_{i}^{n}(+)$ & $\begin{array}{l}\text { Kabupaten Mamuju, } \\
\text { Kabupaten Mamuju } \\
\text { Utara }\end{array}$ & - \\
\hline$r_{i}^{d}<r_{i}^{n}(-)$ & & $\begin{array}{l}\text { Kabupaten Majene, } \\
\text { Kabupaten Polewali } \\
\text { Mandar, Kabupaten } \\
\text { Mamasa, Kabupaten } \\
\text { Mamuju Tengah }\end{array}$ \\
\hline
\end{tabular}

Sumber: Data diolah, (2017)

Berdasarkan Tipologi Klassen Provinsi Sulawesi Barat Tahun 2011-2015 terbagi menjadi dua klasifikasi. Kabupaten Mamuju dan Kabupaten Mamuju Tengah berada di Kuadran I (Pertama), Sedangkan pada Kuadran II (Kedua) dan Kuadran III (Ketiga) tidak ada satupun Kabupaten yang termasuk di Provinsi Sulawesi Barat selama lima tahun terakhir yaitu tahun 2011-2015 dan Kabupaten Majene, Kabupaten Polewali Mandar, Kabupaten Mamasa dan Kabupaten Mamuju Tengah berada di Kuadran IV Keempat).

Dari hasil analisis Tipologi Klassen pola pertumbuhan ekonomi di Povinsi Sulawesi Barat Tahun 2011-2015 dilihat pada gambar: 
Gambar 2.

Pola Pertumbuhan Ekonomi Provinsi Sulawresi Barat

Tahun 2011-2015

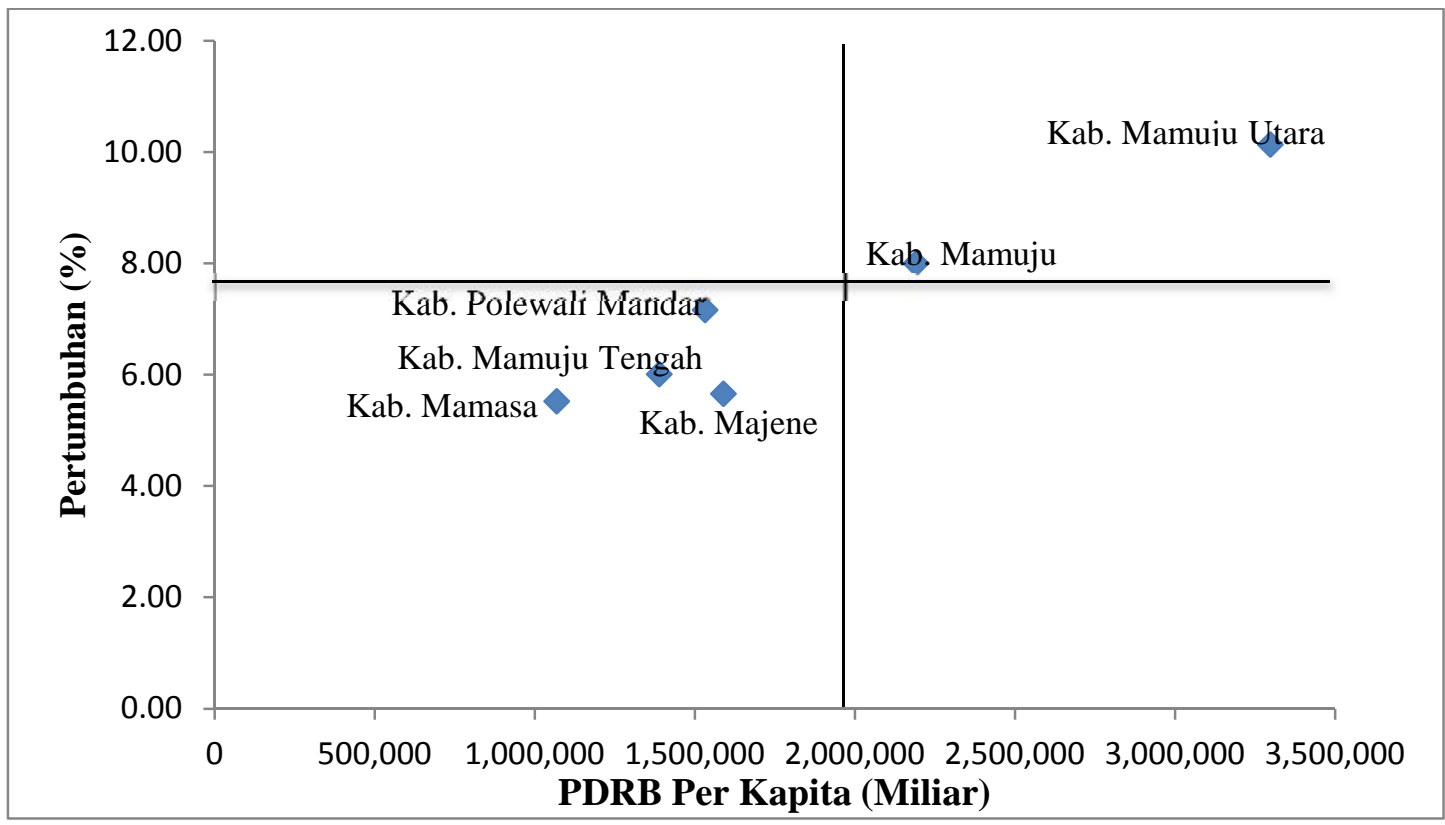

Sumber: Data diolah, (2017)

Hasil penelitian yang dilakukan di Provinsi Sulawesi Barat bahwa Kabupaten Mamuju dan Kabupaten Mamuju Utara termasuk daerah maju dan tumbuh capat ini di karenakan Kabupaten Mamuju dan Kabupaten Mamuju Utara memiliki laju pertumbuhan PDRB yang labih cepat di bandingkan dengan Provinsi. Kedua Kabupaten ini memiliki kondisi geografisnya yang sangat bagus jika dibandingkan dengan Kabupaten lain di Provinsi Sulawesi Barat diantaranya yaitu Kedua kabupaten ini memiliki jumlah penduduk tertinggi kedua dan ketiga serta memiliki sumber daya alam yang paling tinggi di Provinsi Sulawesi Barat, yaitu Kabupaten Mamuju memiliki produksi Kelapa Sawit terbesar kedua dan Kabupaten Mamuju Utara memiliki produksi Kelapa Sawit terbesar di Provinsi Sulawesi Barat. Kelapa Sawit ini merupakan investasi yang sangat besar dan sangat mendorong perekonomian daerah karena Kelapa Sawit merupakan perusahaan yang berproduksi besar serta produksinya di impor sampai keluar negeri.

Selain itu, Kabupaten Mamuju merupakan sebagai ibu kota Provinsi Sulawesi Barat sehingga memiliki pertumbuhan ekonomi yang lebih cepat. 
Kabupaten Mamuju memiliki Lapangan Terbang dan Pelabuhan serta memiliki panjang jalan tertinggi dalam kondisi baik/aspal, sehingga para investor lebih mudah mengakses masuk ke daerah tersebut. Sedangkan Kabupaten Mamuju Utara selain produksi Kelapa Sawit terbesar juga memiliki Pelabuhan yang besar di Pasang Kayu yang dapat di akses para pelayaran luar negeri sehingga ini juga dapat memudahkan para investor besar masuk ke daerah tersebut.

Kabupaten Polewali Mandar, Kabupaten Majene, Kabupaten Mamasa serta Kabupaten Mamuju Tengah termasuk daerah yang relatif tertinggal. Keempat Kabupaten ini lebih rendah laju pertumbuhan ekonomi dan laju pendapatannya jika di bandingkan dengan Provinsi. Kabupaten Polewali Mandar termasuk salah satu daerah relatif tertinggal ini di karenakan laju pertumbuhan dan pendapatannya rendah di banding dengan Provinsi. Kabupaten Polewali Mandar merupakan daerah terluas dan memiliki jumlah penduduk terbanyak di Provinsi Sulawesi Barat. Kegiatan ekonomi Kabupaten Polewali Mandar berkonsentrasi pada kegiatan pertanian dan memiliki produksi tanaman terbesar seperti Padi, Sagu, Kelapa dan Kakao akan tetapi ini tidak mamp mempercepat laju pertumbuhan ekonomi Kabupaten.

Kabupaten Majene juga termasuk daerah relatif tertinggal karena Kabupaten Majene merupakan daerah paling kecil di Provinsi Sulawesi Barat, sehingga Kabupaten Majene memiliki pendapatan PDRB rendah jika di bandingkan dengan Provinsi. Luas daerah yang kecil ditambah lebih dominan daerah pegunungan sehingga menyebabkan akses jalan juga sedikit, sehingga Kabupaten Majene hanya mengandalkan perekonomian di bidan sektor jasa seperti investasi dan bisnis untuk mendorong pendapatan PDRB Kabupaten.

Kabupaten Mamasa salah satu daerah yang termasuk daerah relatif tertinggal karena Kabupaten Mamasa tidak mampu mendorong pendapatan PDRBnya. Kabupaten Mamasa memiliki pendapatan PDRB terendah karena sumber perekonomian sedikit hanya mengandalkan pada sektor pertanian dengan produksi tanaman besar yaitu kopi serta sektor Jasa. Selain itu Kabupaten Mamasa juga memiliki Jumlah penduduk terendah ketiga di Provisi Sulawesi Barat.

Kabupaten Mamuju tengah juga termasuk daerah yang relatif tertinggal. Kabupaten Mamuju Tengah sudah sewajarnya termasuk daerah yang relatif tertinggal karena selain memiliki jumlah penduduk terendah juga Kabupaten 
Mamuju Tengah termasuk Kabupaten termuda yaitu hasil pemekaran dari Kabupaten Mamuju sekitar tahun 2010-2011, sehigga memiliki PDRB terendah karena baru berbenah dan berusaha membangun daerahnya untuk bersain dengan daerah lain.

Pola pertumbuhan ekonomi Provinsi Sulawesi Barat dari tahun 2011 sampai dengan tahun 2015 sebanyak empat Kabupaten yang relatif tertinggal (Kuadran IV), yaitu Kabupaten Majene, Kabupaten Polewali Mandar, Kabupaten Mamasa dan Kabupaten Mamuju Tengah. Keempat Kabupaten ini, pertumbuhan ekonomi dan pendapatan perkapitanya masih rendah jika di bandingkan dengan pertumbuhan ekonomi dan pendapatan perkapita Provinsi Sulawesi Barat. Kabupaten Mamuju dan Kabupaten Mamuju Utara termasuk daerah maju dan tumbuh cepat (Kuadran I), kedua Kabupaten ini memiliki laju pertumbuhan ekonomi dan pendapatan perkapita yang cepat jika dibandingkan dengan Provinsi Sulawesi Barat.

\section{Hasil Analisis Indeks Williamson.}

Berdasarkan hasil perhitungan Indeks Williamson, ketimpangan di Provinsi Sulawesi Barat dapat dilihat pada tabel: 4.3. Dari hasil penelitian menunjukkan ketimpangan yang terjadi antar Kabupaten di Provinsi Sulawesi Barat dari tahun 2011-2015, dari tabel tersebut selama 5 tahun dari tahun 2011 Indeks Williamson terus mengalami meningkat dari tahun ketahun sampai tahun 2015.

Tabel: 4.3

Indeks Williamson antar Kabupaten di Provinsi Sulawesi Barat tahun 2011-2015:

\begin{tabular}{|c|c|}
\hline Tahun & Indeks Williamson \\
\hline 2011 & 0,320 \\
\hline 2012 & 0,335 \\
\hline 2013 & 0,342 \\
\hline 2014 & 0,376 \\
\hline 2015 & 0,383 \\
\hline Rata-rata & $\mathbf{0 , 3 5 1}$ \\
\hline
\end{tabular}

Sumber: Data diolah, (2017)

Hasil penelitian ketimpangan yang terjadi di Provinsi Sulawesi Barat tahun 2011 angka Indeks Williamson adalah 0,320 kemudian mengalami peningkatan di tahun 2012 sebesar 0,335 ini menandakan bahwa kurangnya pemerataan antar 
daerah di Provinsi Sulawesi Barat, dan terus mengalami peningkatan hingga tahun 2015 sebesar 0,383 hal ini menunjukkan bahwa ketimpangan terus melebar.

Pergerakan ketimpangan pada tahun 2013 ketahun 2014 mengalami peningkatan yang tinggi dan tahun 2014 ketahun 2015 tingkat ketimpangan terus mengalami pelebaran. Meskipun ketimpangan terus mengalami peningkatan akan tetapi ketimpangan yang terjadi masih tergolong rendah karena rata-rata ketimpangan yang terjadi sebesar 0,351 masih di bawah 0,5.

Ketimpangan ini terjadi karena adanya konsentrasi kegiatan ekonomi sektor basis di daerah tertentu, sehingga yang menikmati hasilnya hanya sebagian, serta adanya perbedaan sumber daya alam yang di miliki antar Kabupaten sehingga berpengaruh terhadap kondisi lingkungan dan infrastruktur antar daerah. Infrastruktur di bidang kesehatan dan pendidikan harus lebih di utamakan dan ditingkatkan oleh pemerintah Provinsu Sulawesi Barat karena ini merupakan faktor yang sangat menunjang agar sumber daya manusia terus berkembang dan mampu mengelolah sumber daya alam dengan baik agar memiliki nilai tambah yang tinggit demi kemajuan daerah itu sendiri. Pembangunan infrastruktur ini harus harus merata di setiap daerah di Provinsi sulawesi Barat agar ketimpangan antar daerah berkurang atau tidak ada lagi.

\section{Hasil Hipotesis Kuznets Kurva "U-Terbalik".}

Pembuktian kurva "U-Terbalik" dilakukan dengan membuat kurva hubungan antara angka Indeks Williamson dengan pendapatan per kapita untuk itu digunakan Regresion Curve Estimation seperti yang ditunjukkan oleh Gambar 3.

\section{Gambar 3.}

Kurva Pengujian hipotesis Kuznets tentang "U-Terbalik" di Provinsi Sulawesi Barat tahun 2011-2015.

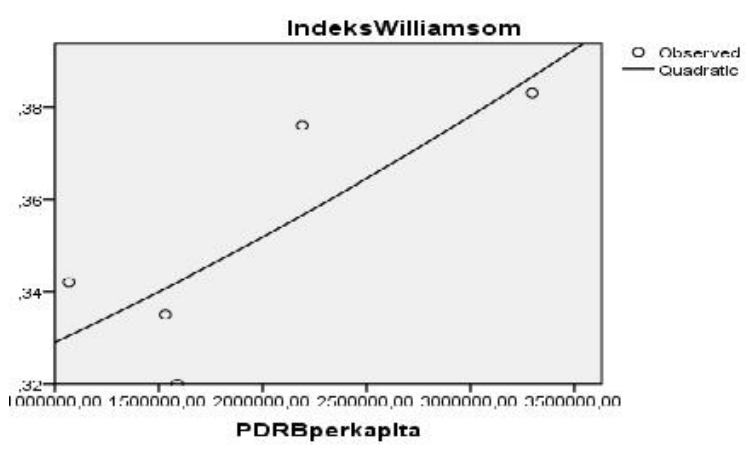

Sumber: Data diolah (2017) 
Hasil penelitian yang dilakukan di Provinsi Sulawesi Barat, bahwa kurva hubungan Indeks Williamson dengan pendapatan perkapita tidak menyerupai sebuah kurva huruf "U-Terbalik", hanya menggambarkan garis miring ke kiri. Ini membuktikan bahwah dalam lima tahun terakhir pertumbuhan ekonomi dan distribusi pendapatan Provinsi Sulawesi Barat tidak merata atau cenderung memburuk, sehingga kurva huruf "U-Terbalik" tidak berlaku di Provinsi Sulawesi Barat selama periode penelitian tahun 2011 sampai dengan tahun 2015.

Pertumbuhan ekonomi dan distribusi pendapatan cenderung memburuk di Provinsu Sulawesi Barat karena adanya perbedaan sumber daya manusia atau perbedaan indeks pembangunan manusia dan sumber daya alam antar daerah serta adanya ketimpangan pembangunan yang labih canderung terhadap daerah yang sudah maju. Sehingga hal ini menyebabkan terjadinya ketidak merataan pertumbuhan ekonomi dan distribusi pendapatan antar daerah di Provinsi Sulawesi Barat.

\section{KESIMPULAN}

Berdasarkan hasil analisis data dan pembahasan yang telah dikemukakan sebelumnya, dapat diambil kesimpulan sebagai berikut:

1. Perbedaaan pola ekonomi antar Kabupaten di Provinsi Sulawesi Barat yaitu: Kabupaten Mamuju dan Kabupaten Mamuju Utara merupakan Kabupaten/daerah maju dan tumbuh cepat, dan Kabupaten Majene, Kabupaten Polewali Mandar, Kabupaten Mamasa, serta Kabupaten Mamuju Tengah termasuk Kabupaten/daerah relatif tertinggal.

2. Provinsi Sulawesi Barat terus mengalami peningkata ketimpangan dalam lima tahun terakhir yaitu tahun 2011 sampai tahun 2015.

3. Hipotesis Kuznets yaitu analisis kurva huruf "U-Terbalik" terhadap pertumbuhan ekonomi Provinsi Sulawesi Barat, bahwa hipotesis Kuznets "U-Terbalik" tidak berlaku di Provinsi Sulawesi Barat selama lima tahun yaitu tahun 2011 sampai tahun 2015, hanya menggambarkan garis miring ke kiri.

\section{DAFTAR PUSTAKA}

Arsyad Lincolin, Ekonomi Pembangunan, STIEYKPN Yogyakarta, Yogyakarta 1999. 
Deliarnov, Perkembangan Pemikiran Ekonomi, Rajawali Pers, Jakarta, 2015

Deni Iswanto, Jurnal. Ketimpangan Pendapatan Antar Kabupaten/kota dan Pertumbuhan Ekonomi di Provinsi JawaTimur. Tangeran Selatan, 2015.

Doni Mahardiki dan Rokhedi Priyo Santoso, Jurnal. Analisis Perubahan Ketimpangan Pendapatan dan Pertumbuhan Ekonomi Antar Provinsi di Indonesia. Semarang, 2013.

Erni Umi Hasanah, dan Danang Sunyoto, Pengantar Ilmu Ekonomi Makro, CAPS ( Center for Academic Pubishing Cervice) Gejayan, Yogyakarta, 2013.

Faktiatun Nadiroh, Artikel, Ketimpangan Pembangunan Antar Wilayah, Banten, 2012.

Fuktiatun Nadirah, Ketimpangan Pembangunan Wilayah, Universitas Sultan Ageng Tirtayasa, Banten, 2016

http://Sulbar.bps.go.id, 2016

Koncoro, Kesenjangan Antar W ilayah, Erlangga, Jakarta, 2003.

Lili Masli, Jurnal, Analisis Faktor-faktor Yang Mempengaruhi Pertumbuhan Ekonomi dan Ketimpangan Regional Antar Kabupaten/kota di Provinsi Jawa Barat. Bandung, 2016

Nanang Martono, Metodologi Penelitian Kuantitatif, Rajawali Pers, Jakarta, 2014 Ngakan Putu Mahesa Eka Raswita dan Made Suyana Utama, J urnal. "Analisis Pertumbuhan Ekonomi dan Ketimpangan Antar Kecamatan di Kabupaten Gianyar". Bali, 2013

N. Gregory Mankiw, Makroekonomi. Erlangga, Jakarta, 2016.

Rachmat Syafe'l, Al-hadis Aqidah, Akhlak, Sosial dan Hukum. Ed. Rev: Pustaka Setia, Bandung, 2000

Rendi Hangga Kusuma, Jurnal, Analisis Struktur Pertumbuhan Ekonomi dan Ketimpangan Pendapatan Antar Daerah di Provinsi Jawa Tengah 20042008, 2011

Richard A. Bilas, Teori Mikroekonomi, PT. Gelora Aksara Pratama, Jakarta, 2010. Robinson, Ekonomi Regional Teori dan Implikasi, PT. Bumi Aksara, Jakarta, 2015 Sadono Sukirno, Makroekonomi Teori Pengantar, Rajawali Pers, Jakarta, 2012. Sadono Sukirno, Pengantarteori Mikroekonomi. Rajawali Pers, Jakarta, 2001. Siti Nur Fatoni, Pengantar Ilmu Ekonomi. Pustaka Setia, Bandung, 2014. Sugiyono, Metode Penelitian Administrasi. Alfabeta, Bandung, 2008. Sjafrizal, Ekonomi Regional Teori dan Aplikasi, Niaga Swadaya, Jakarta, 2008. 
Sjafrizal, Ketimpangan Pembangunan antar Wilayah, Niaga Swadaya, Jakarta, 2003

Todaro, Ekonomi Pembangunan, Erlangga, Jakarta, 2006

Tutik Yuliani, J urnal. Pertumbuhan Ekonomi dan Ketimpangan Pendapatan Antar Kabupaten di Kalimantan Timur, Semarang, 2015.

Undang-undang Republik Indonesia Nomor 26 tahun 2004 tentang Pembentukan Provinsi Sulawesi Barat.

Undang-undang Republik Indonesia Nomor 32 dan 33 tahun 2004 tentang Pemerintahan Daerah. 